\title{
Publisher's Note: Colored noise and memory effects on formal spiking neuron models [Phys. Rev. E 91, 062702 (2015)]
}

\author{
L. A. da Silva and R. D. Vilela
}

(Received 16 March 2016; published 28 March 2016)

DOI: 10.1103/PhysRevE.93.039904

This paper was published online on 8 June 2015 with an omission of Fig. 9. Figure 9 has been replaced online as of 9 March 2016. The figure is incorrect in the printed version of the journal, therefore for the benefit of the print readership, the figure has been replicated below.
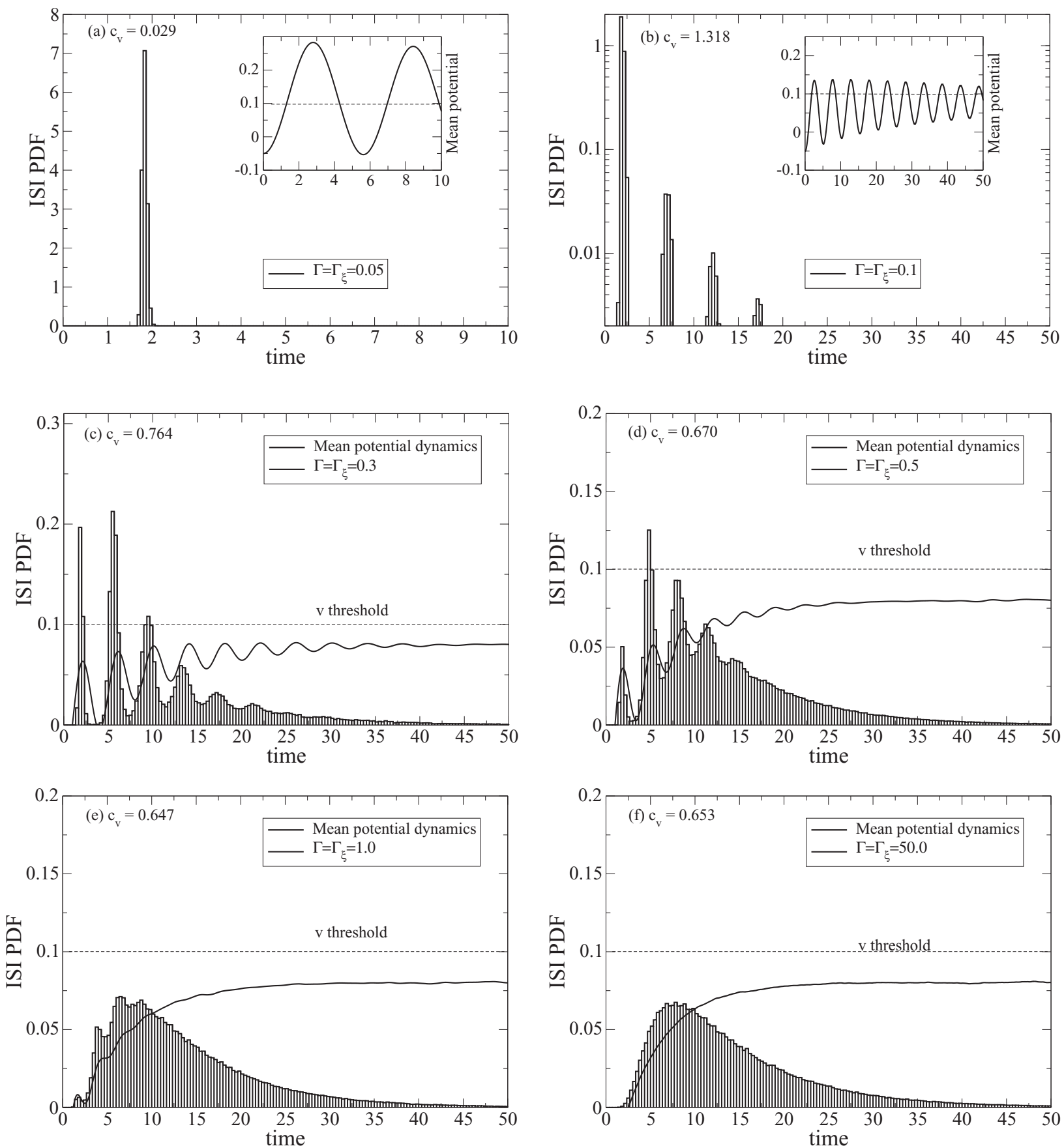

FIG. 9. Emergence of multimodality in the ISI distribution. In all panels: $\mu=0.08$ and $\sigma_{\xi}=0.1$. 